\title{
Razão e emoção: reações ao estado da economia e aprovação do governo federal
}

\author{
Pedro Santos Mundim \\ Wladimir Gramacho \\ André Jácomo de Paula Pinto
}

\section{Introdução}

Estudos sobre o impacto da economia no comportamento político são abundantes na ciência política, especialmente em pesquisas sobre a aprovação governamental ${ }^{1}$. Nenhuma outra área de atuação dos governos, como saúde, educação e segurança, recebeu até aqui tanta atenção dos pesquisadores, especialmente porque as variáveis econômicas quase sempre têm em geral boa capacidade de explicação em modelos multivariados. Outra constatação sobre os estudos que medem a influência do contexto econômico sobre o comportamento político é a concentração das análises nos efeitos dos indicadores econômicos objetivos (Hibbs, 1987; Kinder, 1981; Lewis-Beck, Martini e Kiewiet, 2013) e das percepções cognitivas da opinião pública sobre a situação econômica do país e seu impacto na avaliação dos governos e no voto (Feldman, 1982; Kiewiet, 1981, 1983; Nadeau, Lewis-Beck e Bélanger, 2012).

Contudo, foram poucos os trabalhos que discutiram como a aprovação governamental pode ser explicada pelos sentimentos dos consumidores (Clarke e Stewart, 1994; Erikson, MacKuen e Stimson, 2000; MacKuen, Erikson e Stimson, 1992), e menos ainda os que se ocuparam dos efeitos das reações emocionais em relação à economia (Conover e Feldman, 1986). O objetivo deste artigo, portanto, é contribuir para a compreensão da influência que as emoções em relação ao estado da economia podem ter sobre a avaliação governamental, comparando-as aos efeitos das percepções cognitivas. Até onde soubemos, este é o primeiro trabalho que explora essa relação analisando dados do contexto brasileiro.

Pode-se supor que a avaliação cognitiva sobre a variação dos principais indicadores econômicos ocorra frequentemente de maneira subjetiva e algumas vezes pareça tão idiossincrática que seja difícil explicar sua origem (Veiga e Ross, 2016). Uma hipótese alternativa é que essa percepção sobre a situação econômica do país esteja mediada pelas nossas avaliações afetivas, nossas emoções ou nossos sentimentos em relação à

\footnotetext{
${ }^{1}$ Para revisões de literatura, veja Nannestad e Paldam (1994) e, mais recentemente, Lewis-Beck e Stegmaier (2013) e Berlemann e Enkelmann (2014).
} 
RAZÃO E EMOÇÃO: REAÇÕES AO ESTADO DA ECONOMIA E APROVAÇÃO DO GOVERNO FEDERAL

economia2. Trabalhos como o de Marcus, Neuman e MacKuen (2000), por exemplo, mostraram a importância das emoções na formação das nossas avaliações políticas. Se, como dizem os autores, pensamos em política quando nossas emoções nos dizem para fazê-lo, esse gatilho pode ser acionado também por conta de questões econômicas, que provavelmente afetam nossas percepções cognitivas sobre a atuação do governo nessa área.

Até recentemente, as emoções eram vistas como fonte de irracionalidade (Elster, 1994, 1996). Novos estudos, porém, mostraram que elas, na verdade, auxiliam na tomada de decisão racional, formando uma "inteligência afetiva" (MacKuen et al., 2007; Marcus, 2002; Marcus, Neuman e MacKuen, 2000). Neste artigo, portanto, buscamos estabelecer uma conexão entre a abordagem racionalista-cognitiva e a emocional-afetiva para explicar a avaliação do governo federal, num modelo causal mais abrangente.

Nosso referencial empírico são dois surveys realizados pela Secretaria de Comunicação Social da Presidência da República (Secom-PR) na transição entre o primeiro e o segundo mandatos da ex-presidente Dilma Rousseff (PT). Mais especificamente, em novembro de 2014 e abril de 2015. Cada um deles foi aplicado em contextos econômicos e políticos muito distintos. Em 2014, logo após a disputa que reelegeu a ex-presidente, a avaliação positiva do governo federal ${ }^{3}$ era de $42 \%$. Cinco meses depois, esse juízo somava meros $13 \%$. Nesse mesmo período, a avaliação positiva sobre o estado da economia 4 caiu de $20 \%$ para $8 \%$, enquanto a avaliação negativa ${ }^{5}$ subiu de $26 \%$ para $63 \%$. Ou seja: o contexto dos surveys permite analisar a influência das avaliações cognitivas e emocionais tanto em situações econômicas e políticas moderadamente positivas como naquelas claramente negativas.

No geral, os resultados encontrados estão em consonância com o trabalho de Conover e Feldman (1986) e sugerem que tanto nossas percepções cognitivas quanto nossos sentimentos influenciam as avaliações que os cidadãos têm da atuação do governo federal. Os resultados também apoiam a teoria da inteligência afetiva, sugerindo que certas mudanças no estado da opinião pública talvez não possam ser compreendidas corretamente sem que as emoções e os processos que as envolvem sejam levados em consideração. Finalmente, os resultados também sugerem que as emoções têm maior influência sobre a avaliação do governo federal em momentos de deterioração das condições econômicas ${ }^{6}$.

\footnotetext{
2 Neste artigo o termo "percepções afetivas", ou qualquer um dos seus sinônimos, será utilizado da mesma forma que em Conover e Feldman (1986, p. 51): "um termo genérico abrangendo sentimentos, humores e emoções (...). Em comparação, cognição é 'conhecimento'; este envolve a representação do conhecimento e o processo envolvido na aquisição de tais informações".

3 Soma de respostas "ótimo" e "bom" a respeito do desempenho do governo federal, numa escala formada também pelas opções "regular", "ruim" e "péssimo".

4 Soma de respostas "ótimo" e "bom" a respeito do estado da economia.

5 Soma de respostas "ruim" e "péssimo".

6 Downs (1999, p. 29) argumenta que, por conta da incerteza, o "homem político" do seu modelo teórico "não parecerá ser tanto um personagem de cérebro de máquina de calcular quanto o homem econômico dos utilitaristas". Uma leitura contemporânea de sua obra sugeriria que esse "homem político" downsiano não só
} 
Além dessa contribuição à ampliação dos modelos teóricos que explicam a popularidade governamental, os resultados aqui encontrados também lançam luz sobre um importante componente dos acontecimentos políticos recentes no Brasil que levaram ao impeachment da ex-presidente. As análises sobre a sua destituição não devem ficar restritas às articulações das elites políticas, sejam elas os políticos, os partidos ou a imprensa. Passam, também, pela investigação e a compreensão sobre como ela perdeu o esteio da opinião pública entre 2014 e 20157. Uma das razões pelas quais houve uma perda substantiva da base de apoio ao governo federal encontra-se, como é apresentado a seguir, nos sentimentos negativos que afloraram durante esse período, principalmente entre as pessoas que mudaram de opinião e passaram a reprovar o seu mandato por conta da deterioração do quadro econômico do país.

\section{Avaliação de governo e inteligência afetiva}

Desde os estudos pioneiros de Lazarsfeld, Berelson e Gaudet (1948) sabemos que apenas uma pequena parcela dos cidadãos se interessa e se informa sobre política. A consequência prática desse achado é, como afirmou Popkin (1993, p. 17), a presença disseminada da incerteza na hora em que as pessoas precisam pensar sobre as políticas governamentais e avaliá-las. Esse problema, contudo, é minimizado logo antes ou depois da realização de eleições, quando a atenção dos votantes é aguçada pela necessidade de tomada de decisão e pelas campanhas políticas (Bartels, 1993; Lodge, Steenbergen e Brau, 1995; Marcus e MacKuen, 1993), contexto dos surveys analisados neste artigo.

Popkin (1991, 1993) salientou, corretamente, que uma boa quantidade de informação política relevante está disponível de forma gratuita como um subproduto das nossas atividades diárias. Mas falta a essa leitura um mecanismo explicativo mais claro. Afinal, por que as pessoas deixam sua condição de baixa atenção política e passam a buscar informação para formar suas preferências e avaliações? Para Marcus, Neuman e Mackuen (2000, p. 1), essa mudança de comportamento se dá "quando nossas emoções nos dizem para fazê-lo".

Segundo a teoria da inteligência afetiva, usamos nossas emoções para monitorar os ambientes político e econômico, e fazemos isso através de dois estados mentais formados por fontes distintas - emoção e razão - , que operam em um equilíbrio dinâmico "delicado, interativo e altamente funcional" (Marcus, Neuman e MacKuen, 2000, p. 8) ${ }^{8}$. No âmbito emocional, nosso cérebro comporta dois sistemas independentes e préconscientes, cada um com suas funções específicas e "mutuamente engajados em

tem avaliações cognitivas e racionais como também tem avaliações de origem emocional e que seu comportamento político é afetado por ambas as avaliações.

7 A razão desse argumento vem da influência exercida pela leitura da obra do historiador Darnton (1995), que mostra como os efeitos da literatura de libelo - uma das formas de imprensa da época - sobre a opinião pública ajudam a entender a perda de legitimidade da monarquia francesa no final do século 18.

${ }^{8}$ Autores da área de psicologia, como Kahneman (2011), usam os termos sistema 1 e sistema 2 para referirse, respectivamente, às nossas reações instintivas e emocionais e às nossas ações racionais e refletidas. 
governar nossos pensamentos e comportamentos" (p. 9). O primeiro é o sistema de predisposição, moldado para lidar com questões habituais e que se manifesta nos sentimentos de entusiasmo. O segundo é o sistema de vigilância, moldado para lidar com situações inesperadas e que se manifesta nos sentimentos de ansiedade ${ }^{9}$.

Em momentos de normalidade política ou econômica, as pessoas tendem a manifestar baixo nível de atenção às questões políticas, oferecendo menos espaço para mudanças de humor da opinião pública. Por sua vez, em momentos de crise, um "sistema de alarme emocional" (Marcus, Neuman e MacKuen, 2000, p. 81) é acionado, sinalizando a necessidade de elevar o nível de atenção. Os sentimentos de ansiedade são uma resposta a situações de ameaça, que tiram as pessoas das suas rotinas, fazem-nas mais atentas e alteram seus incentivos para orientar-se (Brader, 2005; MacKuen et al., 2007). Quando afloram, estimulam as pessoas a (i) buscar informação e (ii) conectar resultados das políticas públicas com as ações governamentais, estabelecendo uma relação de responsabilidade.

Por exemplo, ao punirem ou recompensarem os governantes pelas condições da economia do país, as pessoas normalmente são guiadas por suas percepções objetivas. No entanto, tais considerações cognitivas são formadas simultaneamente, se não posteriormente, às reações emocionais, principalmente as derivadas do sistema de vigilância, que as levam tanto "a adquirirem mais informação e informação mais acurada" quanto "a usar essa informação de maneira mais decisiva" (Marcus, Neuman e Mackuen, 2000, p. 113). Esses autores mostraram que, em um período de baixo crescimento econômico, os "apoiadores partidários" são os que se sentem mais ansiosos em relação à figura do presidente, pois a má performance na condução do país ameaça suas convicções partidárias habituais, deixando-os em uma posição desconfortável. Eleitores partidários ansiosos também têm mais chances de abandonar suas predisposições políticas e votar no candidato do "outro partido", pois as "emoções negativas estão associadas com maiores deserções" (p. 112).

Esses elementos nos sugerem que: (i) as avaliações de governo e as decisões políticas podem ser afetadas tanto por dimensões emocionais quanto cognitivas (Ottati e Wyer Jr., 1993); (ii) as reações emocionais geralmente ocorrem primeiro; (iii) esses dois sistemas de avaliação interagem de maneira significativa (Zajonc, 1980), embora sejam distintos e independentes. Como salientaram Conover e Feldman (1986, p. 53), "no grau em que o afeto precede a cognição", e "na medida em que emoções e cognições interagem", as "emoções desempenham um papel-chave na estruturação das percepções das condições econômicas". Portanto, dizem esses autores, modelos de avaliação política ou de performance presidencial que incluem variáveis cognitivas, mas não afetivas, ou vice-versa, estarão mal especificados.

\footnotetext{
${ }^{9}$ Essa discussão é, certamente, mais complexa do que a retratada aqui, como mostram os capítulos 3 e 4 de Marcus, Neuman e MacKuen (2000), mas entendemos ser desnecessário para os objetivos deste artigo detalhar pormenores da teoria da inteligência afetiva, já discutida com propriedade, por exemplo, por Lavareda (2009) e Pimentel Júnior (2010).
} 
Importante observar, por fim, que "reações afetivas podem se formar rapidamente com base numa exposição mínima a um estímulo econômico; avaliações cognitivas, por outro lado, podem se desenvolver mais lentamente e apenas após atenção considerável à informação econômica" (Conover e Feldman, 1986, p. 64). Diante dessa expectativa, seria esperável que variações abruptas no contexto econômico ativassem mais rapidamente as variáveis afetivas que as cognitivas.

Com base na discussão anterior, formulamos cinco hipóteses de trabalho:

H1: o efeito das emoções derivadas do estado da economia brasileira sobre a aprovação do governo federal terá intensidade semelhante quando comparado ao efeito dos juízos cognitivos sobre o contexto econômico nacional, sugerindo um equilíbrio entre as duas dimensões;

H2: o efeito das emoções derivadas do estado das finanças pessoais do entrevistado sobre a aprovação do governo federal terá intensidade semelhante quando comparado ao efeito dos juízos cognitivos sobre o contexto de suas finanças pessoais, sugerindo aqui também um equilíbrio entre as duas dimensões;

H3: a aprovação do governo federal será mais bem explicada pelo conjunto de variáveis sociotrópicas do que pelo conjunto de variáveis egocêntricas, dado o caráter muitas vezes idiossincrático e particular do comportamento das finanças pessoais de cada entrevistado; H4: diante de um contexto de crise econômica, as variáveis emocionais terão efeito mais forte, conforme a expectativa de que as reações afetivas precedem as cognitivas (Conover e Feldman, 1986);

H5: a mudança de opinião sobre o governo federal será mais bem explicada por reações emocionais ao estado da economia do que por juízos cognitivos.

\section{Contexto dos surveys e descrição dos dados}

A eleição presidencial de 2014 representou um divisor de águas após três mandatos petistas no Palácio do Planalto. Dilma Rousseff foi reeleita numa votação apertada, com $51,6 \%$ dos votos válidos, contra 48,4\% do seu concorrente, Aécio Neves (PSDB). Em grande medida, os debates eleitorais estiveram centrados sobre os escândalos de corrupção envolvendo o partido da ex-presidente e a situação da economia, que começava a dar sinais negativos ${ }^{10}$. Ao final daquele ano, a expectativa era de que, passada a disputa pelo voto, duras medidas seriam tomadas para enfrentar problemas como o aumento da inflação, o baixo crescimento econômico e a fragilidade das finanças públicas, ações com grande potencial de piora do humor da opinião pública em relação ao governo federal. Num contexto que nem de longe se assemelhava ao otimismo e à satisfação

10 Ver, por exemplo: "Dilma nega crise econômica e garante inflação dentro da meta em 2014", Folha de S. Paulo, 28 jul. 2014; "Crise econômica e corrupção marcarão a nova presidência", El País, 26 out. 2014. 
produzidos pelo crescimento econômico em 2010, ao final do governo Lula, e registrados no recorde histórico de aprovação presidencial na Nova República ${ }^{11}$.

Ainda que os indicadores econômicos já inspirassem preocupação, as percepções da opinião pública em relação ao estado da economia do país permaneceram estáveis durante a campanha eleitoral. Pesquisas encomendadas pela Secom/PR à empresa Ibope Inteligência mostraram que $20 \%$ dos brasileiros consideravam a situação econômica do país como "ótima" ou "boa" em novembro de 2014, ao passo que esse percentual era de $25 \%$ em julho; e que $25 \%$ classificaram a economia como "ruim" ou "péssima", exatamente na mesma proporção que cinco meses antes ${ }^{12}$. Esses números, contudo, não expressavam o que estaria por vir, como a sucessão de fatos a partir de janeiro de 2015 revelou.

\section{Variáveis afetivas e cognitivas}

As pesquisas da Secom/PR de novembro de 2014 e abril de $2015^{13}$ trouxeram uma bateria de perguntas que buscavam captar as avaliações afetivas dos brasileiros em relação à situação econômica do país (também chamada de versão sociotrópica) e à situação econômica pessoal do entrevistado (também conhecida como versão egocêntrica). A elaboração das questões utilizou desenho semelhante ao adotado por Marcus, Neuman e MacKuen (2000) - reproduzido anteriormente no Brasil por Pimentel Júnior (2007, 2010) - e Conover e Feldman (1986).

Os dois surveys analisados neste artigo contemplam a seguinte pergunta aos brasileiros: "Agora eu gostaria de saber sobre seus sentimentos com relação à economia do país/sua situação econômica pessoal. Não existe resposta certa ou errada, eu quero saber a sua primeira impressão. Nos últimos 12 meses, a economia do país/sua situação econômica pessoal Ihe fez sentir...". Eram lidos, então, oito sentimentos, sendo quatro positivos (confiança, esperança, empolgação e felicidade) e quatro negativos (preocupação, medo, ansiedade e decepção). O questionário alternou um sentimento negativo a cada sentimento positivo lido. Os respondentes poderiam registrar quantas emoções tivessem sentido. Para os que respondessem "sim" a algum dos oito sentimentos,

\footnotetext{
${ }^{11}$ A avaliação positiva do governo Lula (soma de respostas "ótimo" e "bom") chegou a 83\% em novembro de 2010, segundo o instituto Datafolha.

12 Ambas as pesquisas foram aplicadas face a face e contaram com 2002 brasileiros entrevistados em todo o país, de 16 anos ou mais. A seleção de amostra foi probabilística nos dois primeiros estágios, e por cotas de sexo, idade, escolaridade e ramo de atividade no último estágio. A margem de erro é de $\pm 2 \%$, com nível de confiança de $95 \%$. O trabalho de campo das pesquisas foi realizado, respectivamente, entre os dias 10 e 5 de julho, e 22 e 28 de novembro de 2014. Os relatórios das pesquisas encontram-se na página da Secom/PR: <http://www.secom.gov.br/> e também: <http://www.secom.gov.br/atuacao/pesquisa/listade-pesquisas-quantitativas-e-qualitativas-de-contratos-atuais/lista-de-pesquisas-quantitativas-equalitativas-de-contratos-atuais $>$.

13 As informações metodológicas da pesquisa de abril de 2015 são as mesmas das pesquisas de julho e novembro de 2014, com exceção do período de trabalho de campo, que ocorreu entre os dias 11 e 18 de abril.
} 
era feita uma segunda pergunta, que buscava medir sua intensidade a partir de escala ordinal de três pontos: "muito(a), algum(a) ou pouco(a)"14.

A formulação das perguntas seguiu o pressuposto teórico de que a estrutura afetiva possui duas dimensões, uma positiva e outra negativa, e que elas são relativamente independentes (Abelson et al., 1982; Pimentel Junior, 2007). Por isso, antes de realizar quaisquer testes com os dados, os estudos sobre o papel das emoções nas decisões políticas buscam confirmar essa proposição (Conover e Feldman, 1986; Marcus, Neuman e MacKuen, 2000; Pimentel Júnior, 2007, 2010). Essa validação pode ser feita com análises fatoriais e testes de correlação. Espera-se que haja o carregamento de dois fatores independentes, um para cada dimensão afetiva, e que a correlação entre os índices afetivos criados seja fraca ou nula.

Seguimos esses procedimentos e implementamos quatro testes de análises fatoriais confirmatórias com os dados dos surveys de novembro de 2014 e abril de 2015, sendo um para os sentimentos em relação à economia do país e outro para os sentimentos em relação à situação econômica pessoal. Os resultados obtidos mostram que, em cada um dos quatros testes, foram carregados dois fatores independentes, um para cada dimensão afetiva, com correlação fraca entre eles. É importante enfatizar que os resultados da pesquisa de 2015 foram melhores do que os de 2014. Contudo, essas diferenças não foram suficientes para excluirmos a base de dados de 2014 do artigo, ou para impedir o prosseguimento das análises ${ }^{15}$.

Após essa análise confirmatória, foram criados "índices afetivos" a partir do somatório das respostas dos entrevistados para cada tipo de sentimento ${ }^{16}$. Um índice de emoções positivas e outro de emoções negativas sobre o estado da economia nacional. Versões egocêntricas desses índices também foram construídas, nesse caso sobre o estado das finanças pessoais do entrevistado. Originalmente, cada um desses índices obteve valor mínimo de 4 e máximo de 16.

Ainda que a literatura prescreva a operacionalização dos sentimentos sobre o estado da economia nacional (ou das finanças pessoais) em duas dimensões - uma negativa e outra positiva -, incluímos também neste artigo os efeitos de um único índice emocional (em suas versões sociotrópica e egocêntrica) que contemplasse ao mesmo tempo os polos positivo e negativo, o que facilitaria sua comparação com o efeito das respectivas variáveis cognitivas. Por esse motivo, serão apresentadas as duas versões de mensuração das emoções, tanto na versão sociotrópica como na egocêntrica: (i) com dois

\footnotetext{
14 A resposta era única para cada sentimento. Houve rodízio entre os itens. Infelizmente, por razões orçamentárias não foi possível estender a lista de sentimentos, já que o questionário continha outros módulos sobre avaliação de políticas públicas, além de outras demandas. De todo modo, a inclusão dos oito sentimentos ocorreu em função das indicações da literatura especializada (Marcus, Neuman e MacKuen, 2000) e dos resultados dos pré-testes, que confirmaram as expectativas teóricas.

15 Os resultados e gráficos desses testes podem ser solicitados ao primeiro autor do artigo no e-mail <psmundim@ufg.br>.

${ }^{16}$ A confiabilidade média (alfa de Cronbach) dos índices na pesquisa de novembro de 2014 foi 0.85 (DP = 0.02 ) e a dos índices da pesquisa de abril de 2015 foi 0.77 ( $\mathrm{DP}=0.04)$.
} 
índices - um negativo e um positivo - e (ii) com um único índice (unidimensional). A variável com um único índice foi construída a partir da soma de cada uma das emoções reportadas, sendo que as emoções positivas entraram na equação com valores positivos e as emoções negativas com o respectivo signo. Portanto, o índice único de emoções variava originalmente de -16 a +16 . Aqui apresentam-se os valores normalizados, para facilitar a comparação dos coeficientes.

A Tabela 1 traz os dados descritivos dessas variáveis. Eles estão organizados em duas dimensões, uma sociotrópica (que dá conta da avaliação e das emoções sobre o estado da economia do país) e outra egocêntrica (que reporta a avaliação e as emoções sobre o estado da economia pessoal dos entrevistados). A piora do humor da opinião pública sobre as condições econômicas é notável entre os dois surveys. A maior variação, contudo, se dá na demonstração de emoções positivas sobre o estado da economia brasileira $(-0,30)$ e das finanças pessoais $(-0,26)$. As emoções associadas ao pessimismo ou à insatisfação não oscilaram com a mesma intensidade, o que sugere que a maior clareza sobre a crise econômica no início de 2015 tenha diminuído o otimismo e a satisfação dos brasileiros, mas não alterado de forma considerável os sentimentos negativos já presentes na sociedade brasileira em 2014. Importante notar também que os juízos cognitivos também mostraram piora na avaliação da economia do país $(-0,20)$ e das finanças pessoais $(-0,10)$. 
Tabela 1

Médias das variáveis normalizadas cognitivas e afetivas sobre a economia do país e a economia pessoal nos surveys de 2014 e 2015

(desvios-padrão entre parênteses)

\begin{tabular}{|c|c|c|c|}
\hline & Nov. 2014 & Abr. 2015 & Dif. médias \\
\hline \multicolumn{4}{|l|}{ 1. Dimensão sociotrópica (economia do país) } \\
\hline \multicolumn{4}{|l|}{1.1 Variável cognitiva } \\
\hline 1.1.1 EcoPaísCognitiva & $0,47(0,22)$ & $0,27(0,26)$ & $-0,20$ \\
\hline \multicolumn{4}{|l|}{1.2 Variável afetiva } \\
\hline \multicolumn{4}{|l|}{ 1.2.1 Versão com dois índices } \\
\hline 1.2.1.1 EcoPaísEmoçõesPositivas & $0,43(0,29)$ & $0,13(0,21)$ & $-0,30$ \\
\hline 1.2.1.2 EcoPaísEmoçõesNegativas & $0,51(0,30)$ & $0,61(0,31)$ & 0,10 \\
\hline \multicolumn{4}{|l|}{ 1.2.2 Versão com um índice } \\
\hline 1.2.2.1 EcoPaísEmoções (unidimensional) & $0,46(0,16)$ & $0,25(0,20)$ & $-0,21$ \\
\hline \multicolumn{4}{|l|}{ 2. Dimensão egocêntrica (economia pessoal) } \\
\hline \multicolumn{4}{|l|}{2.1 Variável cognitiva } \\
\hline 2.1.1 EcoPessoalCognitiva & $0,57(0,21)$ & $0,47(0,26)$ & $-0,10$ \\
\hline \multicolumn{4}{|l|}{2.2 Variável afetiva } \\
\hline \multicolumn{4}{|l|}{ 2.2.1 Versão com dois índices } \\
\hline 2.2.1.1 EcoPessoalEmoçõesPositivas & $0,55(0,30)$ & $0,29(0,31)$ & $-0,26$ \\
\hline 2.2.1.2 EcoPessoalEmoçõesNegativas & $0,47(0,29)$ & $0,50(0,35)$ & 0,03 \\
\hline \multicolumn{4}{|l|}{ 2.2.2 Versão com um índice } \\
\hline 2.2.2.1 EcoPessoalEmoções (unidimensional) & $0,54(0,16)$ & $0,40(0,26)$ & $-0,14$ \\
\hline
\end{tabular}

Fonte: Elaboração dos autores com base em surveys da Secom/PR (2014, 2015).

Obs.: Todas as variáveis nesta tabela foram normalizadas, portanto variam entre 0 e 1 .

\section{Variáveis dependentes}

A principal variável dependente neste artigo é a aprovação do governo, que foi medida por meio da seguinte questão, simples e direta: "O(A) $\operatorname{Sr}(a)$. aprova ou desaprova o desempenho atual do governo federal?"17. A deterioração do apoio explícito ao desempenho governamental foi nítida, com queda de 35 pontos, diferença entre uma taxa de aprovação de 59\% em 2014 e outra de 23\% em 2015. O survey de abril de 2015 também contemplou uma questão a respeito da mudança de opinião sobre o governo, cuja redação era: "Nos últimos seis meses, o(a) Sr(a). mudou ou não mudou de opinião em relação ao desempenho do governo federal?". Entre os entrevistados, 29\% responderam "sim" a essa pergunta. Os que haviam mudado de opinião respondiam a uma segunda

\footnotetext{
17 As pesquisas da Secom/PR são institucionais, e não pessoais ou partidárias. Por isso, é vedada a menção a quaisquer figuras políticas - inclusive a presidente da República - ou partidos. Daí sempre utilizarem o termo "governo federal". Essa proibição também limitava o escopo de temas que poderiam ser explorados nos questionários, que deveriam se cingir a questões ligadas às ações de comunicação da administração pública (Gramacho, 2014). Ainda que a questão utilizada não mencionasse o nome de Dilma Rousseff, acreditamos que o contexto pós-eleitoral e o fato de que Dilma estivesse iniciando seu segundo mandato deixavam poucas dúvidas aos entrevistados sobre de que governo se tratava.
} 
indagação: "O(A) Sr(a). diria que aprovava e passou a desaprovar ou que desaprovava e passou a aprovar o desempenho do governo federal?". Sem surpresas, $84 \%$ dos que haviam mudado de opinião disseram que tinham passado a desaprová-lo. A Tabela 2 traz as respostas dos entrevistados nos dois surveys a essas questões:

Tabela 2

Aprovação e mudança de opinião em relação ao governo federal (\%)

\begin{tabular}{|l|c|c|c|}
\hline & Nov. 2014 & Abr. 2015 & Dif. \\
\hline Aprova o governo federal & 59 & 23 & -35 \\
\hline Mudou de opinião sobre o governo federal & ND & 29 & ND \\
\hline Passou a desaprovar o governo federal & ND & $87^{*}$ & ND \\
\hline
\end{tabular}

Fonte: Elaboração dos autores com base em surveys da Secom/PR (2014, 2015).

* Percentual calculado sobre os $29 \%$ que disseram haver mudado de opinião sobre o governo federal.

ND: Não disponível.

\section{Variáveis de controle}

Os modelos contemplam dois grupos de variáveis de controle. O primeiro deles descreve as características sociodemográficas dos entrevistados e seu estado de ânimo no momento do início da aplicação do questionário. Foram consideradas variáveis sobre gênero, idade, escolaridade, raça, renda familiar mensal, porte do município (em número de habitantes) e condição do município (capital, periferia ou interior) do entrevistado. 0 estado de ânimo no início da entrevista foi mensurado por meio da questão: "Como o(a) $\operatorname{Sr}(a)$. diria que se sente com relação à vida que vem levando hoje? $\mathrm{O}(\mathrm{A}) \operatorname{Sr}(a)$. está: muito satisfeito, satisfeito, insatisfeito ou muito insatisfeito?".

Já o segundo grupo busca controlar os efeitos de razões instrumentais para a formação da opinião sobre o governo federal. A primeira delas indica simplesmente se o entrevistado era beneficiário do Programa Bolsa Família: 9\% e 12\% dos entrevistados, respectivamente, responderam positivamente a essa pergunta em novembro de 2014 e abril de 2015. A segunda razão considera a nota dada pelos entrevistados para quatro quesitos de desempenho do governo: (i) os serviços públicos, (ii) a saúde pública, (iii) a educação pública e (iv) a segurança pública no Brasil. Utilizou-se uma escala de 0 a 10 , em que 0 significava "totalmente insatisfeito" e 10, "totalmente satisfeito" 18.

Pode-se esperar uma taxa de aprovação maior entre cidadãos que eram beneficiários do programa Bolsa Família ou que avaliavam de forma mais positiva serviços públicos e áreas de atuação do governo como saúde, educação e segurança. Sabe-se que a oferta de serviços públicos é heterogênea no país e que, portanto, diferentes cidadãos

\footnotetext{
18 Estamos cientes da importância da identificação partidária e da ideologia na avaliação presidencial. Contudo, por conta do seu objetivo institucional, as pesquisas da Secom/PR não podem incluir menções a partidos políticos nos seus questionários, mesmo relacionadas à ex-presidente da República, nem perguntas sobre ideologia política. É por esse simples motivo que essas duas variáveis não foram incluídas nos modelos apresentados no artigo.
} 
podem usufruir de serviços públicos com qualidades distintas. Essas variáveis pretendem controlar essa satisfação heterogênea em relação a alguns dos mais relevantes serviços públicos, que com frequência lideram a lista dos principais problemas enfrentados pelos cidadãos no país ${ }^{19}$. A Tabela 3 traz os dados descritivos das variáveis de controle. A variação mais importante entre as duas pesquisas deu-se no desânimo dos entrevistados com a vida que vinham levando e na piora das notas para os serviços públicos em geral, a saúde, a segurança e a educação públicas.

Tabela 3

Dados descritivos sobre as variáveis de controle

\begin{tabular}{|l|c|c|c|}
\hline & Nov. 2014 & Abr. 2015 & Dif. \\
\hline Características dos entrevistados & 52 & 52 & 0 \\
\hline Gênero: mulher (\%) & 33 & 34 & 1 \\
\hline Idade (média) & 58 & 57 & -1 \\
\hline Escolaridade: até ensino médio incompleto ou menor (\%)* & 54 & 58 & +4 \\
\hline Raça: pretos e pardos (\%) & 82 & 90 & +8 \\
\hline Renda familiar: até 5 salários mínimos (\%) & 43 & 44 & +1 \\
\hline Porte do município: até 100 mil habitantes (\%) & 29 & 29 & 0 \\
\hline Condição do município: capital (\%) & 18 & 34 & +16 \\
\hline Ânimo do entrevistado: "muito insatisfeito" + "insatisfeito" (\%) & & & \\
\hline Razões instrumentais para aprovar o governo federal & 9 & 12 & +3 \\
\hline Beneficiário do programa Bolsa Família (\%) & 5,3 & 4,0 & $-1,3$ \\
\hline Avaliação dos serviços públicos (média) & 4,4 & 3,1 & $-1,3$ \\
\hline Avaliação da saúde pública (média) & 5,8 & 4,9 & $-0,9$ \\
\hline Avaliação da educação pública (média) & 4,3 & 3,6 & $-0,7$ \\
\hline Avaliação da segurança pública (média)
\end{tabular}

Fonte: Elaboração dos autores com base em surveys da Secom/PR $(2014,2015)$.

* Por simplicidade, apresenta-se aqui apenas uma categoria da variável. Toda a informação pode ser solicitada por e-mail do primeiro autor deste artigo.

\section{A relação entre medidas afetivas e cognitivas}

A análise dos dados seguiu os passos do artigo de Conover e Feldman (1986). A primeira ação foi estimar as correlações entre as medidas afetivas e cognitivas, com o objetivo de testar a premissa de que essas duas formas de avaliação da economia seriam independentes, como argumentou Zajonc (1980). Os resultados de correlações bivariadas entre as variáveis cognitivas e os índices de emoção (nas versões bidimensional e unidimensional) podem ser vistos na Tabela 4:

19 No survey de 2014 , os problemas mais citados foram relacionados a saúde (18\%), corrupção (17\%), drogas (13\%), segurança (8\%), administração pública (8\%) e educação (7\%). No de 2015 , os principais problemas se referiram a saúde $(25 \%)$, corrupção $(12 \%)$, impostos $(8 \%)$, segurança $(7 \%)$ e administração pública (7\%). "Educação" havia caído para o oitavo posto, com $4 \%$ das citações. 
Tabela 4

Relação entre reações afetivas e cognitivas ao estado da economia

\begin{tabular}{|c|c|c|c|}
\hline \multirow{2}{*}{\multicolumn{2}{|c|}{ Avaliação emocional da... }} & \multicolumn{2}{|c|}{ Avaliação cognitiva da situação... } \\
\hline & & $\begin{array}{c}\text { econômica } \\
\text { do país }\end{array}$ & $\begin{array}{c}\text { econômica } \\
\text { pessoal }\end{array}$ \\
\hline \multicolumn{4}{|l|}{ Nov. 2014} \\
\hline \multirow{3}{*}{ economia do país } & Emoções positivas & $0,23 *$ & $0,19 *$ \\
\hline & Emoções negativas & $-0,21 *$ & $-0,09 *$ \\
\hline & Emoções (unidimensional) & $0,40 *$ & $0,25 *$ \\
\hline \multirow{3}{*}{ economia pessoal } & Emoções positivas & $0,10 *$ & $0,21 *$ \\
\hline & Emoções negativas & $-0,16^{*}$ & $-0,18^{*}$ \\
\hline & Emoções (unidimensional) & $0,24 *$ & $0,37 *$ \\
\hline \multicolumn{4}{|l|}{ Abr. 2015} \\
\hline \multirow{3}{*}{ economia do país } & Emoções positivas & $0,29 *$ & $0,18 *$ \\
\hline & Emoções negativas & $-0,37 *$ & $-0,25^{*}$ \\
\hline & Emoções (unidimensional) & $0,44 *$ & $0,29 *$ \\
\hline \multirow{3}{*}{ economia pessoal } & Emoções positivas & $0,19 *$ & $0,32 *$ \\
\hline & Emoções negativas & $-0,25 *$ & $-0,39 *$ \\
\hline & Emoções (unidimensional) & $0,29 *$ & $0,45^{*}$ \\
\hline
\end{tabular}

Fonte: Elaboração dos autores com base em surveys da Secom/PR $(2014,2015)$.

Todas as entradas são $r$ de Pearson.

Obs.: Por simplicidade, usaremos apenas $* p<0.05$, deixando de informar significância estatística para outros níveis.

Todas as correlações estão na direção esperada: reações emocionais (positivas/negativas) estão associadas com percepções cognitivas (positivas/negativas) sobre a economia, resultado idêntico ao encontrado por Conover e Feldman (1986). Além disso, todas as correlações são fracas ou moderadas, o que mostra que as dimensões afetivas e cognitivas não estão "intimamente ligadas". Um terceiro ponto a se destacar é o aumento, ainda que pequeno, da correlação entre indicadores afetivos e cognitivos de 2014 para 2015. Apesar de a economia ter sido um tema recorrente durante a campanha, em 2014 ainda não havia uma clara percepção da opinião pública sobre a gravidade da crise econômica no país. Foi a partir do início de 2015 que esse juízo se difundiu na sociedade brasileira, seja pela piora substantiva dos indicadores econômicos, seja pelas medidas de ajuste fiscal adotadas no início daquele novo mandato.

\section{Medidas afetivas, cognitivas e aprovação do governo federal}

Esta seção apresenta e discute os resultados de modelos logit que procuram explicar a aprovação do governo federal. Os resultados encontram-se na Tabela 5. Os bancos de dados dos dois surveys foram consolidados num só e a análise contemplou interações que mediram possíveis mudanças de intensidade dos efeitos das variáveis independentes nos dois contextos. Como mencionado anteriormente, para facilitar a 
comparação entre os coeficientes, todas as variáveis incluídas nos modelos foram redimensionadas para a escala $0-1$.

Tabela 5

Coeficientes de regressão logit de modelos que explicam a aprovação do governo federal (2014 e 2015)

\begin{tabular}{|c|c|c|c|c|}
\hline & \multicolumn{4}{|c|}{ Modelos } \\
\hline & (1) & (2) & (3) & (4) \\
\hline \multicolumn{5}{|l|}{ Dimensão sociotrópica (economia do país) } \\
\hline \multirow{2}{*}{ EcoPaísCognitiva } & $2,52 *$ & $2,99 *$ & $2,52 *$ & $2,97 *$ \\
\hline & $(0,22)$ & $(0,33)$ & $(0,22)$ & $(0,33)$ \\
\hline \multirow{2}{*}{ EcoPaísCognitiva $\times$ Survey 2015} & & $-1,11 *$ & & $-1,09 *$ \\
\hline & & $(0,45)$ & & $(0,45)$ \\
\hline \multirow{2}{*}{ EcoPaísEmoçõesPositivas } & $2,11 *$ & $1,86^{*}$ & - & - \\
\hline & $(0,22)$ & $(0,32)$ & - & - \\
\hline \multirow{2}{*}{ EcoPaísEmoçõesPositivas × Survey 2015} & - & $-0,07$ & - & - \\
\hline & - & $(0,47)$ & - & - \\
\hline \multirow{2}{*}{ EcoPaísEmoçõesNegativas } & $-1,79 *$ & $-2,01^{*}$ & - & - \\
\hline & $(0,21)$ & $(0,33)$ & - & - \\
\hline \multirow{2}{*}{ EcoPaísEmoçõesNegativas × Survey 2015} & - & 0,60 & - & - \\
\hline & - & $(0,43)$ & - & - \\
\hline \multirow{2}{*}{ EcoPaísEmoções (unidimensional) } & - & - & $3,87 *$ & $3,82 *$ \\
\hline & - & - & $(0,30)$ & $(0,49)$ \\
\hline \multirow{2}{*}{$\begin{array}{l}\text { EcoPaísEmoções (unidimensional) } \times \\
\text { Survey } 2015\end{array}$} & - & - & - & $-0,69$ \\
\hline & - & - & - & $(0,64)$ \\
\hline Dimensão egocêntrica (economia pessoal) & - & - & - & - \\
\hline \multirow{2}{*}{ EcoPessoalCognitiva } & $0,55 *$ & $0,85^{*}$ & $0,56 *$ & $0,85^{*}$ \\
\hline & $(0,24)$ & $(0,34)$ & $(0,24)$ & $(0,34)$ \\
\hline \multirow{2}{*}{ EcoPessoalCognitiva $\times$ Survey 2015} & & $-0,56$ & & $-0,56$ \\
\hline & & 0,46 & & $(0,46)$ \\
\hline \multirow{2}{*}{ EcoPessoalEmoçõesPositivas } & 0,33 & $0,64 *$ & - & - \\
\hline & $(0,19)$ & $(0,30)$ & - & - \\
\hline \multirow{2}{*}{ EcoPessoalEmoçõesPositivas × Survey2015 } & - & $-0,52$ & - & - \\
\hline & - & $(0,40)$ & - & - \\
\hline \multirow{2}{*}{ EcoPessoalEmoçõesNegativas } & $-0,15$ & $-0,23$ & - & - \\
\hline & $(0,21)$ & $(0,33)$ & - & - \\
\hline \multirow{2}{*}{ EcoPessoalEmoçõesNegativas × Survey 2015} & - & $-0,06$ & - & - \\
\hline & - & $(0,43)$ & - & - \\
\hline \multirow{2}{*}{ EcoPessoalEmoções (unidimensional) } & - & - & 0,49 & $0,92 *$ \\
\hline & - & - & $(0,28)$ & $(0,47)$ \\
\hline \multirow{2}{*}{$\begin{array}{l}\text { EcoPessoalEmoções (unidimensional) } \times \\
\text { Survey } 2015\end{array}$} & - & - & - & $-0,53$ \\
\hline & - & - & - & $(0,58)$ \\
\hline
\end{tabular}




\begin{tabular}{|c|c|c|c|c|}
\hline & \multicolumn{4}{|c|}{ Modelos } \\
\hline & (1) & (2) & (3) & (4) \\
\hline \multicolumn{5}{|l|}{ Controles } \\
\hline \multirow{2}{*}{ Mulher } & 0,06 & 0,03 & 0,07 & 0,03 \\
\hline & $(0,09)$ & $(0,10)$ & $(0,09)$ & $(0,10)$ \\
\hline \multirow{2}{*}{ Idade } & $-0,34$ & $-0,30$ & $-0,30$ & $-0,28$ \\
\hline & $(0,25)$ & $(0,25)$ & $(0,24)$ & $(0,25)$ \\
\hline \multirow{2}{*}{ Escolaridade } & $-0,57^{*}$ & $-0,57^{*}$ & $-0,57^{*}$ & $-0,57^{*}$ \\
\hline & $(0,22)$ & $(0,22)$ & $(0,22)$ & $(0,22)$ \\
\hline \multirow{2}{*}{$\begin{array}{l}\text { Raça: pretos e pardos } \\
\text { (referência: outras) }\end{array}$} & 0,18 & $0,18^{*}$ & 0,17 & $0,18^{*}$ \\
\hline & $(0,10)$ & $(0,10)$ & $(0,09)$ & $(0,10)$ \\
\hline \multirow{2}{*}{ Renda familiar mensal } & $-0,45$ & $-0,58^{*}$ & $-0,46$ & $-0,59 *$ \\
\hline & $(0,26)$ & $(0,27)$ & $(0,26)$ & $(0,27)$ \\
\hline \multirow{2}{*}{ Porte do município } & $-0,05$ & $-0,03$ & $-0,03$ & $-0,03$ \\
\hline & $(0,23)$ & $(0,23)$ & $(0,23)$ & $(0,23)$ \\
\hline \multirow{2}{*}{$\begin{array}{l}\text { Condição do município: capital } \\
\text { (referência: interior) }\end{array}$} & 0,07 & 0,05 & 0,05 & 0,04 \\
\hline & $(0,15)$ & $(0,15)$ & $(0,14)$ & $(0,15)$ \\
\hline \multirow{2}{*}{$\begin{array}{l}\text { Condição do município: periferia } \\
\text { (referência: interior) }\end{array}$} & 0,19 & 0,11 & $0,22^{a}$ & 0,12 \\
\hline & $(0,13)$ & $(0,14)$ & $(0,13)$ & $(0,14)$ \\
\hline \multirow{2}{*}{ Recebe Bolsa Família } & 0,09 & 0,14 & 0,10 & 0,15 \\
\hline & $(0,15)$ & $(0,16)$ & $(0,15)$ & $(0,16)$ \\
\hline \multirow{2}{*}{ Avaliação dos serviços públicos } & $0,69 *$ & $0,71 *$ & $0,72 *$ & $0,70 *$ \\
\hline & $(0,26)$ & $(0,26)$ & $(0,26)$ & $(0,26)$ \\
\hline \multirow{2}{*}{ Avaliação da saúde pública } & $0,54 *$ & $0,47 *$ & $0,55 *$ & $0,46 *$ \\
\hline & $(0,23)$ & $(0,23)$ & $(0,23)$ & $(0,23)$ \\
\hline \multirow{2}{*}{ Avaliação da educação pública } & $1,08^{*}$ & $1,07 *$ & $1,10^{*}$ & $1,07 *$ \\
\hline & $(0,24)$ & $(0,24)$ & $(0,24)$ & $(0,24)$ \\
\hline \multirow{2}{*}{ Avaliação da segurança pública } & $-0,70 *$ & $-0,59 *$ & $-0,71^{*}$ & $-0,59 *$ \\
\hline & $(0,21)$ & $(0,21)$ & $(0,21)$ & $(0,21)$ \\
\hline \multirow{2}{*}{ Estado de ânimo do entrevistado } & $1,45^{*}$ & $1,43^{*}$ & $1,49 *$ & $1,44^{*}$ \\
\hline & $(0,26)$ & $(0,27)$ & $(0,26)$ & $(0,27)$ \\
\hline \multirow{2}{*}{ Constante } & $-2,70^{*}$ & $-2,80^{*}$ & $-4,75^{*}$ & $-5,04 *$ \\
\hline & $(0,34)$ & $(0,40)$ & $(0,33)$ & $(0,42)$ \\
\hline \multirow{2}{*}{ Survey2015 } & - & 0,28 & - & $0,80^{*}$ \\
\hline & - & $(0,36)$ & - & $(0,37)$ \\
\hline $\mathrm{N}$ & 3207 & 3207 & 3207 & 3207 \\
\hline Nagelkerke R-sq & 0.47 & 0.48 & 0,47 & 0.48 \\
\hline Classificados corretamente (\%) & 78,5 & 79,2 & 78,3 & 79,3 \\
\hline -2 Log-likelihood & 2969,51 & 2934,93 & 2975,86 & 2937,12 \\
\hline
\end{tabular}

Fonte: Elaboração dos autores com base em surveys da Secom/PR $(2014,2015)$.

Obs.: Por simplicidade, usaremos apenas $* p<0.05$, deixando de informar significância estatística para outros níveis.

Os resultados dos quatro modelos apresentados na Tabela 5 apoiam o sentido geral das hipóteses elaboradas. Todos os coeficientes das variáveis afetivas têm o sinal esperado. As estimativas dos sentimentos positivos em relação à economia (do país e pessoal) têm sinais positivos, ou seja, aumentaram a probabilidade de aprovação do governo, enquanto as estimativas dos sentimentos negativos têm sinais negativos, ou seja, diminuíram essa chance. Além disso, os coeficientes têm grandezas próximas aos das variáveis cognitivas, tanto quando comparados na dimensão sociotrópica, que trata da economia do país (H1), quanto em sua dimensão egocêntrica, orientada à economia pessoal do entrevistado $(\mathrm{H} 2)$. 
Os resultados mostram também que a dimensão sociotrópica é muito mais importante que a egocêntrica quando se trata de predizer as chances de aprovação do governo federal pelos cidadãos, reforçando nossa expectativa (H3). Essa é mais uma indicação de que os cidadãos, por mais que sejam indivíduos autointeressados, tendem a dar maior peso à dimensão sociotrópica nas suas avaliações dos governos (Edlin, Gelman e Kaplan, 2007; Fiorina, 1981; Kiewiet, 1983). Além disso, o achado está em consonância não apenas com a literatura como também suporta expectativas mais razoáveis de que o exercício do accountability vertical se dê pelo desempenho dos governos no âmbito público e coletivo, e menos pelo efeito particular que diferentes políticas públicas possam ter sobre os cidadãos.

Enquanto os modelos 1 e 3 mediram efeitos médios dessas variáveis cognitivas e emocionais nos dois surveys, os modelos 2 e 4 exploraram a influência da crise aflorada em 2015 sobre esses efeitos. Nossa expectativa (H4) era de que a crise econômica aumentaria o efeito das variáveis emocionais, devido ao fato de as reações afetivas precederem as cognitivas (Conover e Feldman, 1986). O resultado, contudo, não mostrou variação estatisticamente significativa nos coeficientes das variáveis afetivas de 2014 para 2015, nem na dimensão sociotrópica, nem na egocêntrica. O que os modelos revelaram foi uma diminuição significativa, em termos estatísticos e substantivos, dos coeficientes da variável cognitiva sociotrópica, sugerindo menor racionalidade na imputação de responsabilidades pelo estado da economia nacional em abril de 2015 e maior importância das emoções depois que o governo inaugurou um ajuste fiscal e os preços começaram a subir e o desemprego passou a crescer.

A partir dos coeficientes do modelo 2, simulamos os efeitos da interação significativa entre a avaliação cognitiva da economia e a mudança de contexto econômico. Em 2014, os que consideravam que o estado da economia brasileira era "péssimo" (EcoPaísCognitiva $=0$ ) tinham $17 \%$ de probabilidade de aprovar o governo, mantendo todos os demais valores das variáveis independentes em suas médias. Contudo, se esse juízo fosse "ótimo" (EcoPaísCognitiva=1), a probabilidade subia a $80 \%$, uma diferença de expressivos 63 pontos. Já em 2015, a mesma simulação produziu, respectivamente, probabilidades de $7 \%$ e $58 \%$. O efeito máximo dessa variável, portanto, passou a ser de 51 pontos. Ou seja, as emoções ganharam importância relativa não porque sua influência tenha aumentado, mas porque se manteve semelhante enquanto o efeito da variável sociotrópica cognitiva diminuiu.

Quanto às variáveis de controle, vale mencionar que a aprovação do governo não diferiu entre gêneros, idades, porte ou condição do município, e sequer entre os beneficiários e não beneficiários do programa Bolsa Família. Entretanto, aprovavam mais o governo federal os brasileiros com menor escolaridade e renda familiar (em dois dos quatro modelos) e os pretos e pardos, sugerindo que os anos de políticas públicas dirigidas a ambos os segmentos sociais possam ter resultado em maior boa vontade com o governo entre esses cidadãos. Sem surpresas, também aprovavam mais o governo federal os que 
avaliavam positivamente os serviços públicos, a saúde pública e a educação pública. Curiosamente, entrevistados que avaliam positivamente a segurança pública tinham menor probabilidade de aprovar o governo federal, possivelmente porque o apoio ao sistema público de segurança é maior entre cidadãos mais conservadores, que tinham menor afinidade programática com o governo Dilma Rousseff. Finalmente, o governo foi mais aprovado entre aqueles entrevistados que se disseram, antes da entrevista, "satisfeitos" ou "muito satisfeitos" com a vida que vinham levando. Um resultado que reforça a importância em compreender o estado emocional (geral ou associado a âmbitos específicos, como a economia) dos cidadãos ao analisar seu comportamento político.

\section{Medidas afetivas, cognitivas e a mudança de opinião sobre o governo federal}

Os modelos que buscaram explicar a aprovação do governo federal com base em variáveis afetivas e cognitivas sobre a economia do país e a pessoal trouxeram evidências a favor das nossas hipóteses e sugerem a coexistência de mecanismos racionais e emocionais de imputação de responsabilidades sobre resultados econômicos. Mas ainda resta distinguir os papéis das emoções e da cognição na decisão de passar a reprovar um governo. Com base na literatura, podemos esperar que as reações afetivas ao novo contexto de 2015 podem ter sido muito mais relevantes que os juízos cognitivos na transformação do estado da opinião pública com relação à administração de Rousseff (H5).

Conforme mencionado anteriormente, o survey de abril de 2015 incluiu duas perguntas explícitas sobre a mudança de opinião a respeito do governo "nos últimos seis meses": 29\% dos entrevistados declararam haver mudado de opinião e $87 \%$ destes afirmaram que tinham passado a reprovar o governo federal. Ou seja, extrapolando esses percentuais para o conjunto da população, um em cada quatro brasileiros declarava que havia passado a reprovar a gestão do governo federal.

Pesquisas qualitativas deram pistas importantes sobre as possíveis razões para que a reprovação ao governo federal tivesse crescido de forma tão importante em pouco tempo. Participantes de grupos de discussão contratados pela Secom/PR e realizados antes do survey de abril de 2015 disseram-se enganados pela retórica eleitoral da então presidente, que havia negado a existência de uma crise econômica e a necessidade de ajustes. Eram apontadas falhas na comunicação do governo, que, na opinião dos participantes, não esclarecia as razões para um aumento tão repentino no preço da gasolina e nas contas de luz. Além disso, era comum a visão de que o governo não conseguia se defender das acusações de corrupção na Petrobras, que envolviam políticos e auxiliares próximos à presidente e aos principais partidos que integravam sua coalizão eleitoral. De fato, o survey de 2015 confirmava a importância desses argumentos. Entre os que passaram a reprovar o governo federal, as principais razões de mudança de opinião foram "a má administração", "o aumento da inflação", "o descumprimento de promessas", "os escândalos de corrupção" e "o aumento de impostos". Juntas, essas justificativas 
somavam $62 \%$ das razões citadas em primeiro lugar pelos entrevistados como razões para a mudança de opinião ${ }^{20}$.

Como num contexto de ameaça e perigo os cidadãos têm mais estímulos para buscar informação (Marcus, Neuman e MacKuen, 2000), os brasileiros provavelmente aumentaram seu nível de exposição ao conteúdo midiático, então dominado pela cobertura da operação Lava Jato e da crise econômica, dois temas em que o enquadramento predominante seria naturalmente negativo à imagem do governo. Além disso, se escândalos de corrupção em contextos de crescimento econômico podem ser menos prejudiciais à popularidade dos governantes (Carlin, Love e Martínez-Gallardo, 2014), em momentos de penúria financeira são gatilhos naturais para estimular sentimentos negativos 21 .

A Tabela 6 apresenta os resultados de modelos de regressão logit que pretendem identificar as variáveis mais importantes dessa mudança de opinião. A variável dependente tem valor " 1 " para todos os que passaram a desaprovar o governo federal e valor " 0 " para os demais casos. Um modelo utilizou a versão bidimensional das emoções e o outro, a versão unidimensional.

\section{Tabela 6}

Coeficientes de regressão logit de modelos que explicam a decisão de passar a desaprovar o governo federal (2015)

\begin{tabular}{|l|c|c|}
\hline \multirow{2}{*}{ Dimensão sociotrópica (economia do país) } & \multicolumn{2}{|c|}{ Modelos } \\
\hline \multirow{2}{*}{ EcoPaísCognitiva } & & $\mathbf{( 1 )}$ \\
\hline \multirow{2}{*}{ EcoPaísEmoçõesPositivas } & $-0,46$ & $-0,46$ \\
\cline { 2 - 3 } & $(0,27)$ & $(0,27)$ \\
\cline { 2 - 3 } EcoPaísEmoçõesNegativas & $-0,28$ & - \\
\hline \multirow{2}{*}{ EcoPaísEmoções (unidimensional) } & $0,34)$ & - \\
\cline { 2 - 3 } & $(0,26)$ & - \\
\hline Dimensão egocêntrica (economia pessoal) & - & $-1,41^{*}$ \\
\hline \multirow{2}{*}{ EcoPessoalCognitiva } & - & $(0,38)$ \\
\hline \multirow{2}{*}{ EcoPessoalEmoçõesPositivas } & $-0,62^{*}$ & $-0,62^{*}$ \\
\hline \multirow{2}{*}{ EcoPessoalEmoçõesNegativas } & $(0,26)$ & $(0,26)$ \\
\hline \multirow{2}{*}{ EcoPessoalEmoções (unidimensional) } & 0,15 & - \\
\cline { 2 - 3 } & $(0,22)$ & - \\
\cline { 2 - 3 } & $-0,27$ & - \\
\cline { 2 - 3 } & $(0,22)$ & - \\
\cline { 2 - 3 }
\end{tabular}

20 Os itens escolhidos como opções de resposta foram definidos a partir das análises de 24 grupos focais, realizados em quatro capitais do país - Porto Alegre, Rio de Janeiro, Salvador e Recife -, pela pesquisa qualitativa da Secom/PR sobre o "ajuste econômico". A aplicação dessa bateria no questionário permitiu inferir, nacionalmente, as percepções obtidas a partir da rodada de pesquisa qualitativa.

${ }^{21} \mathrm{Em}$ modelos de regressão que incluíram as oito emoções isoladamente, o sentimento de decepção com o estado da economia do país foi o preditor mais forte da reprovação ao governo, seguido pela preocupação e pela ansiedade. Infelizmente, a bateria de sentimentos não contemplou a raiva, que merece ser considerada em pesquisas futuras. 


\begin{tabular}{|c|c|c|}
\hline & Modelos & Modelos \\
\hline & (1) & (1) \\
\hline \multicolumn{3}{|l|}{ Controles } \\
\hline \multirow{2}{*}{ Mulher } & 0,12 & 0,13 \\
\hline & $(0,12)$ & $(0,12)$ \\
\hline \multirow{2}{*}{ Idade } & 0,24 & 0,32 \\
\hline & $(0,32)$ & $(0,31)$ \\
\hline \multirow{2}{*}{ Escolaridade } & $0,57^{*}$ & $0,58 *$ \\
\hline & $(0,28)$ & $(0,28)$ \\
\hline \multirow{2}{*}{$\begin{array}{l}\text { Raça: pretos e pardos } \\
\text { (referência: outras) }\end{array}$} & 0,17 & 0,17 \\
\hline & $(0,12)$ & $(0,12)$ \\
\hline \multirow{2}{*}{ Renda familiar mensal } & 0,52 & 0,51 \\
\hline & $(0,33)$ & $(0,33)$ \\
\hline \multirow{2}{*}{ Porte do município } & $-0,50$ & $-0,50$ \\
\hline & $(0,30)$ & $(0,30)$ \\
\hline \multirow{2}{*}{$\begin{array}{l}\text { Condição do município: capital } \\
\text { (referência: interior) }\end{array}$} & 0,10 & 0,09 \\
\hline & $(0,19)$ & $(0,19)$ \\
\hline \multirow{2}{*}{$\begin{array}{l}\text { Condição do município: periferia } \\
\text { (referência: interior) }\end{array}$} & $-0,11$ & $-0,11$ \\
\hline & $(0,20)$ & $(0,20)$ \\
\hline \multirow{2}{*}{ Recebe Bolsa Família } & 0,04 & 0,06 \\
\hline & $(0,18)$ & $(0,18)$ \\
\hline \multirow{2}{*}{ Avaliação dos serviços públicos } & 0,00 & 0,01 \\
\hline & $(0,28)$ & $(0,28)$ \\
\hline \multirow{2}{*}{ Avaliação da saúde pública } & 0,18 & 0,16 \\
\hline & $(0,28)$ & $(0,28)$ \\
\hline \multirow{2}{*}{ Avaliação da educação pública } & 0,40 & 0,43 \\
\hline & $(0,26)$ & $(0,26)$ \\
\hline \multirow{2}{*}{ Avaliação da segurança pública } & $-0,20$ & $-0,18$ \\
\hline & $(0,25)$ & $(0,25)$ \\
\hline \multirow{2}{*}{ Estado de ânimo do entrevistado } & $-0,19$ & $-0,20$ \\
\hline & $(0,26)$ & $(0,26)$ \\
\hline \multirow{2}{*}{ Constante } & $-1,58^{*}$ & $-0,98 *$ \\
\hline & $(0,41)$ & $(0,37)$ \\
\hline $\mathrm{N}$ & 1693 & 1693 \\
\hline Nagelkerke R-sq & 0.05 & 0.05 \\
\hline Classificados corretamente (\%) & 73,4 & 73,5 \\
\hline-2 Log-likelihood & 1894,51 & 1894,51 \\
\hline
\end{tabular}

Fonte: Elaboração dos autores com base em surveys da Secom/PR (2014, 2015).

Obs.: Por simplicidade, usaremos apenas $* p<0.05$, deixando de informar significância estatística a outros níveis.

Nesta tabela, coeficientes com sinal positivo indicam aumento da chance de passar a reprovar o governo federal.

Em que pese o baixo poder explicativo dos modelos, em parte decorrente do fato de que a literatura nessa área tenha avançado mais na explicação sobre determinantes de aprovação dos governos que na compreensão sobre a mudança de opinião sobre eles, os resultados substantivos da análise indicam que os brasileiros que passaram a desaprovar o governo federal entre a eleição de 2014 e a pesquisa de abril de 2015 haviam sido movidos essencialmente por reações emocionais ao estado da economia nacional22. É

22 Entendemos a preocupação de alguns leitores com os baixos valores do $\mathrm{R}^{2}$ da Tabela 6 . Contudo, acreditamos que os resultados são consistentes com a interpretação apresentada. Os modelos são teoricamente coerentes, principalmente com as variáveis disponíveis nos bancos de dados. Além disso, como 
notável que a variável cognitiva sobre a economia nacional não seja estatisticamente significativa. Aparentemente, a mudança de opinião não correspondeu a um juízo racional sobre o novo contexto econômico, mas a uma reação emocional. Foram as emoções negativas sobre a situação econômica do país as que tiveram maior efeito explicativo, indicando que a mudança de humor da opinião pública no Brasil foi mais estimulada pela preocupação, pelo medo, pela ansiedade e pela decepção causados nos primeiros meses do segundo mandato da presidente. A mudança nas opiniões sobre o governo federal, portanto, seguiu antes um padrão de "inteligência afetiva" que de mera "racionalidade". Curioso observar também que a percepção cognitiva sobre as finanças pessoais dos entrevistados também teve um papel importante, ainda que com efeito menor. Entrevistados que consideravam o estado das suas economias pessoais como "ruim" ou "péssimo" tinham mais chance de passar a desaprovar a gestão. Entre as variáveis de controle, apenas a escolaridade apresentou resultado estatisticamente significativo, sugerindo que os mais escolarizados passaram a reprovar em maior medida o governo do que os brasileiros com menor grau de escolaridade.

\section{Conclusão}

Entre 2014 e 2015, o país passou de um contexto de estabilidade das percepções sobre a economia, em que não havia uma clara percepção da crise, para outro, em que os seus sinais negativos começavam a ser sentidos de maneira mais evidente. Do ponto de vista afetivo, o novo momento era propício à emergência de sentimentos como medo, ansiedade e decepção, sobretudo depois de um período tão longo de crescimento sustentado e de melhoria das condições de vida da população.

Os resultados apresentados neste artigo mostram que as emoções, em especial as negativas, sobre a situação econômica do país e, em menor medida, sobre a situação econômica pessoal dos cidadãos desempenham um papel importante na aprovação do governo federal e na mudança de opinião sobre ele. Em consonância com os achados de Conover e Feldman (1986), mesmo incluídos preditores de tipo cognitivo nos modelos, as emoções têm efeitos consideráveis e consistentes. Além disso, no caso de agravamento das condições econômicas, as reações emocionais têm ainda maior importância, sugerindo que a "inteligência afetiva" responda mais rapidamente ao novo contexto que os juízos racionais.

Em suma, as análises de ambas as variáveis dependentes deste artigo reforçam nosso entendimento de que - também no Brasil - a formação da opinião pública sobre o desempenho dos governos responde a fatores tanto emocionais quanto cognitivos, e que os primeiros precedem os segundos. Do ponto de vista teórico, esses resultados melhoram a nossa capacidade explicativa da avaliação dos governantes e reforçam outros estudos

mostrou King (1986), um $\mathrm{R}^{2}$ baixo está longe de comprometer a consistência estatística dos modelos de regressão. 
que defendem a integração de variáveis afetivas e cognitivas à análise do comportamento político dos cidadãos. Conforme lembram Conover e Feldman (1986, p.64), "medidas cognitivas podem não conseguir detectar a maior parte do impacto político das condições econômicas". Em outras palavras, ignorar o efeito de reações emocionais ao estado da economia pode produzir modelos subespecificados.

Parece recomendável, portanto, que pesquisas de avaliação de governo contemplem indicadores tanto afetivos quanto cognitivos em seus questionários e na análise de modelos multivariados. Segundo os resultados deste artigo, em períodos de crise, o sistema de vigilância e os sentimentos negativos tornam-se protagonistas. Cidadãos têm aversão à perda (Kahneman e Tversky, 1979; Tversky e Kahneman, 1974). Isso os faz punir duramente os incumbentes em períodos de desaceleração econômica, levando a uma forte queda nos índices de popularidade; mas a recompensá-los apenas de maneira suave nos períodos de recuperação (Fiorina e Shepsle, 1989; Lau, 1982).

Entre o final de 2014 e o primeiro semestre de 2015, o Brasil passou por uma grande mudança no cenário econômico, com enormes impactos políticos. Nesse sentido, tão importante quanto evidenciar a relevância de variáveis afetivas sobre a economia na avaliação do governo federal, é vislumbrar como elas nos ajudam a dar sentido à narrativa da nossa história política. Uma das razões pelas quais houve uma perda substantiva da base de apoio ao governo federal encontra-se justamente nos sentimentos negativos que afloraram durante esse período, provavelmente em maior medida entre eleitores que votaram pela reeleição de Dilma Rousseff, mas que deixaram de apoiá-la logo no início de seu segundo mandato.

Estudos futuros sobre o papel das emoções na formação da opinião sobre o desempenho dos governos deveriam discriminar melhor a influência de cada um desses sentimentos (Isbell, Ottati e Burns, 2006), o que é uma limitação do presente artigo. Em especial, em diferentes contextos econômicos - de forte crescimento, de normalidade ou de crise - seria esperável que distintas emoções guiassem a formação da opinião dos cidadãos sobre o desempenho governamental. Por exemplo, a bonança poderia estimular uma associação maior entre o sentimento de confiança e a aprovação do governo, assim como a recessão poderia vincular a decepção às opiniões sobre os governantes. Além disso, crises econômicas acompanhadas de casos de corrupção poderiam ir além e incentivar o surgimento de raiva na sociedade. A instabilidade da economia brasileira é, infelizmente, campo fértil para pesquisas futuras nessa área.

Pedro Santos Mundim - Faculdade de Ciências Sociais. Universidade Federal de Goiás, Goiânia (GO), Brasil. E-mail: <psmundim@ufg.br>.

Wladimir Gramacho - Faculdade de Comunicação, Departamento de Jornalismo. Universidade de Brasília, Brasília (DF), Brasil. E-mail: <wggramacho@gmail.com>.

André Jácomo de Paula Pinto - Faculdade de Ciência Política, Centro Universitário UDF, Brasília (DF), Brasil. E-mail: <jacomo.andre@gmail.com>. 


\section{Referências bibliográficas}

Abelson, R. P., et al. "Affective and semantic components in political person perception". Journal of Personality and Social Psychology, vol. 42, n 4, p. 619-630, 1982.

BARTELS, L. M. "Messages received: the political impact of media exposure". American Political Science Review, vol. 87, n², p. 267-285, 1993.

Berlemann, M.; ENKelmanN, S. "The economic determinants of U.S. presidential approval: a survey". European Journal of Political Economy, vol. 36, p. 41-54, 2014.

BRADER, T. "Striking a responsive chord: how political ads motivate and persuade voters by appealing to emotions". American Journal of Political Science, vol. 49, n², p. 388-405, 2005.

Carlin, R. E.; Love, G. J.; Martínez-Gallardo, C. "Cushioning the fall: scandals, economic conditions, and executive approval". Political Behavior, vol. 37, p. 109-130, 2014.

Clarke, H. D.; StewART, M. C. "Prospections, retrospections, and rationality: the "bankers" model of presidential approval". American Journal of Political Science, vol. 38, n 4, p. 1.104-1.123, 1994.

Conover, P. J.; FELDMAN, S. "Emotional reactions to the economy: I'm mad as hell and I'm not going to take it anymore". American Journal of Political Science, vol. 30, n 1, p. 50-78, 1986.

DARNTON, R. Os best-sellers proibidos da França pré-revolucionária. São Paulo: Companhia das Letras, 1995.

Downs, A. Uma teoria econômica de democracia. São Paulo: Edusp, 1999.

EdLin, A.; Gelman, A.; KAPLAN, N. "Voting as a rational choice: why and how people vote to improve the well-being of others". Rationality and Society, vol. 19, n³, p. 293-314, 2007.

ELSTER, J. Peças e engrenagens das ciências sociais. Rio de Janeiro: Relume Dumará, 1994.

1996. "Rationality and the emotions". The Economic Journal, vol. 106, n 438, p. 1.386-1.397,

ERIKSON, R. S.; MACKUEN, M.; STIMSON, J. A. "Bankers or peasants revisited: economic expectations and presidential approval". Electoral Studies, vol. 19, n² 2-3, p. 295-312, 2000.

Feldman, S. "Economic self-interest and political behavior". American Journal of Political Science, vol. 26, n०3, p. 446-466, 1982.

FIORINA, M. P. Retrospective voting in American nacional elections. New Haven; London: Yale University Press, 1981.

FIORINA, M. P.; SHEPSLE, K. A. "Is negative voting an artifact?". American Journal of Political Science, vol. 33, n², p. 423-443, 1989.

GramaCHo, W. "A pesquisa governamental de opinião pública: razões, limites e a experiência recente no Brasil". Revista do Serviço Público, vol. 65, no 1, p. 49-64, 2014.

HiBBS, D. A. The American political economy. Cambridge: Harvard University Press, 1987.

IsBelL, L. M.; OTTATI, V. C.; BURNS, K. C. Affect and politics: effects on judgment, processing, and information seeking. In: REDLAWSK, D. P. (org.). Feeling politics: emotion in political information processing. New York: Palgrave Macmillan, p. 57-86, 2006.

KAHNEMAN, D. Thinking, fast and slow. New York: FSG Books, 2011.

KAHNEMAN, D.; TVERSKY, A. "Prospect theory: an analysis of decision under risk". Econometrica, vol. $47, n^{\circ} 2$, p. 263-292, 1979. 
RAZÃO E EMOÇÃO: REAÇÕES AO ESTADO DA ECONOMIA E APROVAÇÃO DO GOVERNO FEDERAL

KIEWIET, D. R. "Policy-oriented voting in response to economic issues". American Political Science Review, vol. 75, n², p. 448-459, 1981.

KIEWIET, D. R. Macroeconomics and micropolitics: the electoral effects of economic issues. Chicago and London: The University of Chicago Press, 1983.

KInDER, D. R. "Presidents, prosperity, and public opinion". Public Opinion Quarterly, vol. 45, p. 1-21, 1981.

KING, G. "How not to lie with statistics: avoiding common mistakes in quantitative political science". American Journal of Political Science, vol. 30, p. 666-687, 1986.

LAU, R. R. "Negativity in political perception". Political Behavior, vol. 4, n 4, p. 353-377, 1982.

LAVAREDA, A. Emoções ocultas e estratégias eleitorais. São Paulo: Objetiva, 2009.

LAZARsfeld, P. F.; Berelson, B.; GAUDET, H. The people's choice: how the voter makes up his mind in a presidential election. $6^{\mathrm{a}}$ ed. New York: Columbia University Press, 1948.

LEWIS-BeCK, M. S.; MARTINI, N. F.; KIEWIET, D. R. "The nature of economic perceptions in mass publics". Electoral Studies, vol. 32, n 3, p. 524-528, 2013.

LEWIS-BeCK, M. S.; StegmaieR, M. "The VP-function revisited: a survey of the literature on vote and popularity functions after over 40 years". Public Choice, vol. 157, n 3, p. 367-385, 2013.

Lodge, M.; Steenbergen, M. R.; Brau, S. "The responsive voter: campaign information and the dynamics of candidate evaluation". American Political Science Review, vol. 89, n² 2, p. 309-236, jun. 1995.

MACKuen, M.; ERIKSON, R. S.; Stimson, J. A. "Peasants or Bankers? The American electorate and the U.S. economy". The Amerincan Political Science Review, vol. 86, n 3, p. 597-611, 1992.

MACKUEN, M., et al. The third way: the theory of affective intelligence and American democracy. In: NEUMAN, W. R., et al. (orgs.). The affect effect: dynamics of emotion in political thinking and behavior. Chicago: The University of Chicago Press, p. 124-151, 2007.

MARCuS, G. E. The sentimental citizen: emotion in democratic politics. University Park: The Pennsylvania State University Press, 2002.

MarCUS, G. E., et al. The measure and mismeasure of emotion. In: RedLawSK, D. P. (org.). Feeling politics: emotion in political information processing. New York: Palgrave Macmilla, p. 31-45, 2006.

MARCUS, G. E.; MACKUen, M. "Anxiety, enthusiasm, and the vote: the emotional underpinnings of learning and involvement during presidential campaigns". American Political Science Review, vol. 87, n०3, p. 672-685, 1993.

Marcus, G. E.; Neuman, W. R.; MacKuen, M. Affect intelligence and political judgment. Chicago: The University of Chicago Press, 2000.

NADeAu, R.; Lewis-BeCK, M. S.; BÉlAnger, E. "Economics and elections revisited". Comparative Political Studies, vol. 46, n 5, p. 551-573, 2012.

NANNESTAD, P.; PALDAM, M. "The VP-function: a survey of the literature on vote and popularity functions after 25 years". Public Choice, vol. 79, n 3-4, p. 213-245, 1994.

OTTATI, V. C.; WYER JR., R. S. Affect and political judgement. In: IYengaR, S.; MCGUiRE, W. J. (orgs.). Explorations in political psychology. Durham and London: Duke University Press, p. 297-315, 1993.

PIMENTEL JÚNiOR, J. "Razão e emoção no voto: o caso da eleição presidencial de 2006". Dissertação de Mestrado, Departamento de Ciência Política, Universidade de São Paulo. São Paulo, 2007. 
. "Razão e emoção: o voto na eleição presidencial de 2006". Opinião Pública, vol. 16, n², p. $516-541,2010$.

POPKIN, S. L. The reasoning voter: communication and persuasion in presidential elections. $2^{a}$ ed. Chicago and London: The University of Chicago Press, 1991.

Information shortcuts and the reasoning voter. In: GrofmAn, B. (org.). Information, participation and choice: an economic theory of democracy in perspective. Ann Arbor: The University of Michigan Press, p. 17-35, 1993.

TVERSKY, A.; KAHNEMAN, D. "Judgment under uncertainty: heuristics and biases". Science, vol. 185, n 4.157, p. 1.124-1.131, 1974.

VEIGA, L.; Ross, S. D. "Os determinantes da avaliação da economia na eleição presidencial brasileira em 2014". Opinião Pública, vol. 22, n 3, p. 524-549, 2016.

ZAJONC, R. "Feeling and thinking: preferences need no inferences". The American Psychologist, vol. $35, n^{\circ} 2$, p. 151-175, 1980.

\section{Resumo}

Razão e emoção: reações ao estado da economia e aprovação do governo federal

O artigo analisa os efeitos dos juízos cognitivos e das reações emocionais ao estado da economia brasileira e das finanças pessoais de entrevistados em dois surveys sobre a aprovação do governo federal. Com base na teoria da inteligência afetiva, o artigo mensura e compara a influência dessas duas perspectivas sobre a opinião pública brasileira em dois contextos distintos. Em novembro de 2014, a presidente Dilma Rousseff havia sido recém-reeleita e a percepção predominante sobre o estado da economia era satisfatória. Já em abril de 2015, o governo havia anunciado duras medidas de ajuste fiscal e aumento de preços públicos, alterando de modo relevante a opinião da sociedade brasileira sobre o contexto econômico. Nossos resultados confirmam a expectativa de que razão e emoção atuam de modo complementar na formação da opinião sobre o governo federal e que, em tempos de crise, a influência relativa das emoções é maior.

Palavras-chave: emoções; inteligência afetiva; avaliação de governo; crise econômica; Dilma Rousseff

\section{Abstract \\ Reason and emotion: reactions to the state of the economy and federal government approval}

The article analyzes the effects of cognitive judgments and emotional reactions to the state of the economy and the personal finances of respondents in two surveys on the approval of the Brazilian federal government. Based on the theory of affective intelligence, the work measures and compares the influence of these two perspectives on Brazilian public opinion in two different contexts. In November 2014, President Dilma Rousseff had recently been re-elected and the prevailing perception of the state of the economy was quite good. As early as April 2015, the government announced harsh measures of fiscal adjustment and increased public prices, completely reshaping the opinion of Brazilians on the economy. Our results confirm the expectation that reason and emotion act in a complementary way in forming public opinion about the federal government and that, in times of crisis, the relative influence of emotions is greater.

Keywords: emotions; affective intelligence; government assessment; economic crisis; Dilma Rousseff 
RAZÃO E EMOÇÃO: REAÇÕES AO ESTADO DA ECONOMIA E APROVAÇÃO DO GOVERNO FEDERAL

\section{Resumen}

Razón y emoción: reacciones al estado de la economía y aprobación del gobierno federal

El artículo analiza los efectos de los juicios cognitivos y de las reacciones emocionales al estado de la economía brasileña y de las finanzas personales de entrevistados en dos encuestas sobre la aprobación del gobierno federal. A partir de la teoría de la inteligencia afectiva, el trabajo mensura y compara la influencia de esas dos perspectivas sobre la opinión pública brasileña en dos contextos distintos. En noviembre de 2014, la presidenta Dilma Rousseff había sido recién reelegida y la percepción predominante sobre el estado de la economía era satisfactoria. En abril de 2015, sin embargo, el gobierno había anunciado duras medidas de ajuste fiscal y aumento de precios públicos, lo que produjo un cambio bastante relevante en la opinión de la sociedad brasileña sobre el contexto económico. Nuestros resultados confirman la expectativa de que la razón y la emoción actúan de manera complementaria en la formación de la opinión sobre el gobierno federal y que, en tiempos de crisis, la influencia relativa de las emociones es mayor.

Palabras clave: emociones; inteligencia afectiva; evaluación de gobierno; crisis económica; Dilma Rousseff

\section{Résumé}

Raison et émotion: réactions à l'état de l'économie et approbation du gouvernement fédéral

Cet article analyse les effets des jugements cognitifs et des réactions émotionnelles à l'état de l'économie brésilienne et des finances personnelles des personnes interrogées dans deux enquêtes sur l'approbation du gouvernement fédéral. Sur la base de la théorie de l'intelligence affective, I' article mesure et compare l'influence de ces deux points de vue sur le public brésilien dans deux contextes différents. En Novembre 2014, la présidente Dilma Rousseff avait été récemment réélue et la perception qui prévalait sur l'état de l'économie était satisfaisante. En avril 2015, toutefois, le gouvernement avait annoncé de sévères mesures d'ajustement budgétaire et l'augmentation des prix publics, ce qui avait beaucoup fait changer I'opinion de la société brésilienne sur le contexte économique. Les résultats confirment l'espoir que la raison et l'émotion agissent de manière complémentaire dans la formation de l'opinion sur le gouvernement fédéral et que, en temps de crise, l'influence relative des émotions est plus grande.

Mots-clés: émotions; intelligence affective; évaluation du gouvernement; crise économique; Dilma Rousseff

Artigo submetido à publicação em 31 de julho de 2017. Versão final aprovada em 8 de fevereiro de 2018. 
Opinião Pública, DOI 10.1590/1807-01912019271325 errata

\section{Errata}

Errata ao artigo "Razão e emoção: reações ao estado da economia e aprovação do governo federal", de Pedro Santos Mundim, Wladimir Gramacho e André Jácomo de Paula Pinto, publicado no periódico Opinião Pública, vol. 24, n. 1, p. 90-113, com número de DOI 10.1590/1807-0191201924190, na página 109, ao final da página, em filiação dos autores:

- Onde se lia: Wladimir Gramacho (...) Universidade de Brasília, DF, Goiás, Brasil. (...)

Leia-se: Wladimir Gramacho (...) Universidade de Brasília, Brasília, DF, Brasil. (...)

- Onde se lia: André Jácomo de Paula Pinto (...) Centro Universitário UDF, Brasília, DF, Goiás, Brasil. (...)

Leia-se: André Jácomo de Paula Pinto (...) Centro Universitário UDF, Brasília, DF, Brasil. (...)

Opinião Pública adota a licença Creative Commons CC-BY. 